\title{
Diabetes and evidence of atherosclerosis are major risk factors for adverse outcome after elective thoracic aortic surgery
}

\author{
Christian Hagl, MD \\ Jan D. Galla, MD, $\mathrm{PhD}^{\mathrm{a}}$ \\ David Spielvogel, $\mathrm{MD}^{\mathrm{a}}$ \\ Carol Bodian, DrPH \\ Steven L. Lansman, MD, PhD \\ Rafael Squitieri, MD ${ }^{\mathrm{a}}$ \\ M. Arisan Ergin, MD, $\mathrm{PhD}^{\mathrm{a}}$ \\ Randall B. Griepp, MD ${ }^{\mathrm{a}}$
}

From the Departments of Cardiothoracic Surgery $^{\mathrm{a}}$ and Biomathematics, ${ }^{\mathrm{b}}$ Mount Sinai School of Medicine, New York University, New York, NY.

Received for publication Aug 22, 2002; revisions requested Oct 8,2002 ; revisions received Nov 16, 2002; accepted for publication Dec 2, 2002.

Address for reprints: Christian Hagl, MD, Hannover Medical School, Department of Thoracic and Cardiovascular Surgery, CarlNeuberg-Strasse 1, 30625, Hannover, Germany (E-mail: chagl@ hotmail.com).

J Thorac Cardiovasc Surg 2003;126: $1005-12$

Copyright $\odot 2003$ by The American Association for Thoracic Surgery

$0022-5223 / 2003 \$ 30.00+0$

doi:10.1016/S0022-5223(03)00604-4
Background: To predict risk after elective repair of ascending aorta and aortic arch aneurysms, we studied 464 consecutive patients.

Methods: Adverse outcome (stroke or hospital death) was analyzed in 372 patients who underwent proximal repair and 92 patients who underwent aortic arch replacement from 1986 to the present. Preoperative risk factors with a $P$ value less than .2 in a univariate analysis were entered into a multivariate model, and an equation incorporating independent risk factors was derived separately for proximal aorta and arch surgery.

Results: Age more than 65 years $(P=.04)$, diabetes $(P=.02)$, cause $(P=.01)$, and prolonged total cerebral protection time (duration of hypothermic circulatory arrest and selective cerebral perfusion, $P=.001$ ) were significant univariate risk factors for elective proximal aortic repair. Diabetes $(P=.005$, odds ratio 5.1), atherosclerosis $(P=.003$, odds ratio 4.0$)$, and dissection $(P=.048$, odds ratio 2.5$)$ were independent factors. For elective arch surgery, female sex $(P=.07)$, age more than 65 years $(P=.04)$, coronary artery disease $(P=.02)$, diabetes $(P=.06)$, cause $(P$ $=.07)$, and prolonged total cerebral protection time $(P=.025)$ were univariate risk factors. Female sex $(P=.05$, odds ratio 4.7$)$, coronary artery disease $(P=.02$, odds ratio 6.5), diabetes $(P=.13$, odds ratio 4.0$)$, and total cerebral protection time ( $P$ $=.03$, odds ratio $1.02 / \mathrm{min}$ ) were independent factors. To calculate risk of adverse outcome $(P)$, enter 1 if factor is present, 0 if absent, and estimate total cerebral protection time (in minutes).

$\mathbf{P}_{\text {proximal aorta }}=\{1+\exp [3.06-1.62$ (diabetes) -1.37 (atherosclerosis) -0.91 (dissection) $]\}^{-1}$

$\mathbf{P}_{\text {aortic arch }}=\{1+\exp [4.93-1.55$ (female) -1.87 (coronary artery disease)

$$
-1.38 \text { (diabetes) }-0.024 \text { (total cerebral protection time) }]\}^{-1}
$$

Conclusion: In this large series of patients, the presence of diabetes and manifestations of atherosclerosis emerge as extremely important risk factors for adverse outcome after ascending aorta or arch surgery, displacing age. Multivariate equations derived from these data allow more precise calculation of risk for each individual contemplating elective surgery. 


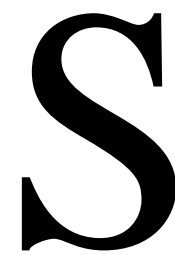

udden rupture or dissection of the thoracic aorta is often a fatal complication of aortic aneurysms in the ascending aorta and aortic arch. Those patients who survive long enough to undergo emergency surgery experience a higher morbidity and mortality than patients who have elective operations. But even elective surgery, especially if the patients are elderly or the lesion involves the aortic arch, carries with it a considerable risk of adverse outcome (AO): death or permanent neurologic disability. Accordingly, to make the best decision regarding the timing of elective surgery or the appropriateness of considering conservative strategies, one should be able to estimate not only the risk of rupture for each patient but also the risk of AO after elective surgery.

At present, the decision to perform elective surgery on the ascending aorta and arch is determined principally by the aortic diameter. In a natural history study, Coady and coworkers ${ }^{1}$ showed that a diameter in the ascending aorta of more than $6 \mathrm{~cm}$ increases the probability of rupture by $30 \%$. An ascending aortic diameter of $6 \mathrm{~cm}$ has therefore become widely accepted as an indication for ascending aorta replacement, although favorable results of elective surgery have tended to decrease the threshold to 5 or $5.5 \mathrm{~cm}$ in some institutions and in some subsets of patients. In addition to aneurysm diameter, several other factors (eg, the existence of Marfan syndrome) are considered to increase risk of rupture and therefore predispose patients to early elective surgery.

The current study more accurately estimates the risk of AO (defined as in-hospital death or permanent stroke) associated with elective surgery of the ascending aorta and the aortic arch. On the basis of the results of elective surgery in a consecutive series of patients, equations to predict the likelihood of AO were derived from 2 separate multivariate risk analyses, depending on the site of surgery. By use of these equations, we can now provide a better estimate of risk for an individual patient undergoing elective repair of the proximal ascending aorta with an open distal anastomosis or elective combined repair of the ascending aorta and the aortic arch.

\section{Patients and Methods \\ Patient Characteristics}

All 464 patients who underwent elective thoracic aortic operations with hypothermic circulatory arrest (HCA) through a median sternotomy at Mount Sinai Hospital from July 1986 to December 1999 were reviewed. The median age was 64 years ( $8-88$ years), and 312 patients $(67 \%)$ were male. A total of 112 patients $(24 \%)$ had undergone previous cardiac or aortic operations. The underlying aortic pathology was chronic dissection in 121 patients (26\%) and atherosclerosis in 103 patients (22\%); patients were classified as having an atherosclerotic aneurysm on the basis of calcification on computed tomographic scan or evidence of atherosclerotic disease in other vessels. A total of 149 patients (32\%) were classified with degenerative aneurysms (featuring cystic medial necrosis), 56 pa-
TABLE 1. Characteristics of proximal and total arch operations

\begin{tabular}{lcc}
\hline & $\begin{array}{c}\text { Proximal repair } \\
\text { (n = 372) }\end{array}$ & $\begin{array}{c}\text { Total arch } \\
\text { (n= 92) }\end{array}$ \\
\hline Aortic valve replacement & & \\
$\quad$ None & $115(30.9 \%)$ & $69(75 \%)$ \\
$\quad$ Biologic & $81(21.8 \%)$ & $7(7.6 \%)$ \\
$\quad$ Mechanical & $176(47.3 \%)$ & $16(17.4 \%)$ \\
Bentall procedure & & \\
$\quad$ Button & $247(66.4 \%)$ & $17(18.5 \%)$ \\
Cabrol & $8(2.2 \%)$ & $1(1.2 \%)$ \\
Classic & $7(1.9 \%)$ & $3(3.3 \%)$ \\
Concomitant procedures & & \\
$\quad$ None & $278(74.7 \%)$ & $74(80.4 \%)$ \\
CABG & $77(20.7 \%)$ & $17(18.5 \%)$ \\
Others & $17(4.6 \%)$ & $2(2.2 \%)$ \\
Crossclamp time & $141 \pm 46$ & $140 \pm 54$ \\
Cardiopulmonary bypass time & $218 \pm 61$ & $230 \pm 62$ \\
TCPT & $25 \pm 9$ & $62 \pm 27$ \\
Minimal esophageal temperature & $13 \pm 3$ & $12 \pm 2$ \\
\hline
\end{tabular}

$T C P T$, Total cerebral protection time, as defined in the text; $C A B G$, coronary artery bypass grafting.

tients $(12 \%)$ with annuloaortic ectasia, and 21 patients $(4.5 \%)$ with the features of Marfan's syndrome. A history of hypertension was the most common general preoperative risk factor (50\%), followed by a history of smoking (45\%) and diabetes mellitus $(5.6 \%)$. Approximately $10 \%$ of the patients had a neurologic history of carotid artery disease, transient ischemic attack, prolonged reversible ischemic deficit, or frank stroke.

\section{Adverse Outcome and Neurologic Evaluation}

AO was defined as in-hospital death or permanent stroke. As in previous studies, patients were considered to have had strokes if they experienced the onset of clinical focal deficits postoperatively or had a focal lesion confirmed by computed tomography scan or magnetic resonance imaging. Patients with neurologic signs or symptoms that resolved before discharge were classified as having had transient strokes, distinguishing them from those with persisting deficits.

\section{Operative Technique}

All operations were performed through a median sternotomy. A Bentall procedure was the most common operation for proximal aortic repair. For total arch replacement, the Mount Sinai "Y-arch" technique was frequently used. ${ }^{2}$ Basic intraoperative data concerning the surgical technique and extent of operation are shown in Table 1.

Cardiopulmonary bypass and HCA were performed as previously described. ${ }^{3}$ The technique is based on alpha-stat blood gas management, thorough cooling to achieve an esophageal temperature of $10^{\circ} \mathrm{C}$ to $13^{\circ} \mathrm{C}$, jugular bulb saturation monitoring, ${ }^{4}$ and topical cooling of the head. Methylprednisolone was used before the onset of HCA, and additional doses were given if HCA duration exceeded 30 minutes.

To minimize neurologic complications, several cerebral protection techniques were used. Selection of the perfusion method was 
made by the surgeons. The majority of patients $(89 \%)$ were treated with HCA alone. HCA was combined with retrograde cerebral perfusion $(\mathrm{RCP})$ in 20 patients. Selective antegrade cerebral perfusion (ACP) was used in 26 patients, exclusively in the total arch replacement group. A combination of selective cerebral perfusion and RCP was used in 7 patients with aortic arch operations. The surgical technique for these cerebral perfusion alternatives has been described in detail. ${ }^{2}$ Because patients in the study underwent operations during a period of 13 years, there were several changes in the cerebral perfusion regimen over time. RCP was used for a few years in patients with a high risk of embolization as the result of atheroma, but it was not used during the last 2 years of the study and was shown to be without benefit in experimental ${ }^{5}$ and clinical studies. $^{2}$ In contrast, selective antegrade perfusion, frequently in combination with right axillary or left subclavian cannulation, was more frequently used during the last 2 years of the study, particularly when more extensive operations were anticipated.

The term total cerebral protection time (TCPT) is invoked, as in previous studies, ${ }^{2}$ to compare cerebral protection using different techniques. TCPT is defined as the time needed to perform any technical maneuvers that require interruption of normal antegrade perfusion. In the HCA group, TCPT corresponds to the interval of circulatory arrest; in the RCP group, TCPT is equal to the total length of HCA including any intervals of RCP; and in the ACP group, it is the sum of the duration of HCA and of selective ACP.

\section{Statistical Methods}

The data were entered in Excel (Microsoft Corp, Redmond, Wash) spreadsheets and converted to a SAS data set (SAS Institute, Inc, Cary, NC) for statistical analysis. Separate analyses were performed for each procedure. Important individual factors associated with AOs were identified by chi-square tests. Bivariate analyses were conducted to look for the potential influence of associations among risk factors. Multivariate logistic regression models were developed to identify significant independent factors. Selected factors were reintroduced into the models produced by the stepwise procedure to check that they did not add significant independent information. The final models were converted to probability estimates through the equation $\operatorname{Pr}(\mathrm{AO})=\{1+\exp -(\mathrm{A}+$ $\left.\left.\mathrm{B}^{\prime} \mathrm{X}\right)\right\}^{-1}$, where $\mathrm{X}$ is a vector of risk factor values, $\mathrm{A}$ is the estimated constant, and B is a vector of estimated coefficients. Confidence intervals for estimated probabilities were constructed on the basis of the estimated covariance matrix.

\section{Results}

AO, defined as in-hospital death or permanent neurologic deficit, occurred in 45 of 464 patients (9.7\% overall). The distribution of the events contributing to $\mathrm{AO}$ in relation to the extent of the operation is given in Table 2 .

\section{Proximal Repair}

Univariate analysis for AO in operations involving the ascending aorta with an open distal anastomosis revealed a number of significant preoperative risk factors, as shown in Table 3: age more than 65 years $(P=.04)$, cause $(P=.01)$, and diabetes $(P=.02)$. Factors considered that did not reach a $P$ value of less than .20 in the univariate analysis
TABLE 2. Outcome after proximal or total arch replacement

\begin{tabular}{lcc}
\hline & $\begin{array}{c}\text { Proximal repair } \\
(\mathbf{n}=\mathbf{3 7 2})\end{array}$ & $\begin{array}{c}\text { Total arch } \\
(\mathbf{n}=\mathbf{9 2})\end{array}$ \\
\hline Hospital death & $27^{*}$ & $8 \S$ \\
Permanent stroke & 10 & 7 \\
Transient stroke & 14 & 1 \\
\hline
\end{tabular}

*Includes 5 deaths after a stroke.

§lncludes 2 deaths after a stroke.

include sex, history of smoking, hypertension, reoperation, and previous neurologic history. The impacts of cause and diabetes on $\mathrm{AO}$ are illustrated in Figures 1 and 2, respectively. The only intraoperative variable significant as a risk factor for AO was TCPT $(P=.001)$.

In the multivariate analysis, only diabetes $(P=.005$, odds ratio $[\mathrm{OR}] 5.1)$, atherosclerosis $(P=.003$, OR 4.0), and dissection $(P=.048$, OR 2.5) emerged as independent risk factors for $\mathrm{AO}$.

\section{Total Arch Replacement}

Age more than 65 years $(P=.04)$ and the presence of coronary artery disease $(\mathrm{CAD})(P=.02)$ were the only significant preoperative risk factors for $\mathrm{AO}$ in the univariate analysis of aortic arch operations (Table 4), although female sex $(P=.07)$, atherosclerosis as the underlying cause $(P=$ $.07)$, and diabetes $(P=.06)$ were of borderline significance. The impacts of cause and diabetes on $\mathrm{AO}$ are seen in Figures 1 and 2. Other factors considered that did not reach a $P$ value less than .20 in the univariate analysis include a history of smoking, hypertension, neurologic history, and additional coronary artery bypass grafting or other concomitant surgical procedure. Of the intraoperative factors, only TCPT had a significant impact on outcome $(P=.025)$.

In the multivariate analysis of aortic arch operations, female sex $(P=.05$, OR 4.7), the presence of CAD $(P=$ .02 , OR 6.5), and TCPT $(P=.03$, OR $1.02 / \mathrm{min})$ were independent risk factors for AO. Because we were able to show that diabetes had a strong impact on outcome after elective ascending aorta surgery, and because only a few patients with arch surgery had diabetes, albeit with an AO of $43 \%$ (Figure 1), we believed it was appropriate to explore the impact of diabetes in the multivariate model. With diabetes included in the model, the same independent risk factors for AO emerged, with only minor changes in the ORs. Patients with diabetes are probably at a 4-fold higher risk for AO after arch surgery than patients without diabetes $(P=.13)$.

\section{Probability of AO}

From the foregoing analysis, we can derive the following equations to predict the risk of $\mathrm{AO}$. To calculate risk of $\mathrm{AO}$ (P), enter 1 if present, 0 if absent, and estimate TCPT (in minutes). 
TABLE 3. Preoperative factors predicting adverse outcome in the univariate $(P<.2)$ and multivariate analysis of 372 patients who underwent elective proximal repair

\begin{tabular}{|c|c|c|c|c|c|}
\hline Preoperative factors & (n) & $\begin{array}{l}\text { Jverse outcome } \\
\text { number }(\%)\end{array}$ & Univariate & Odds ratio & Multivariate \\
\hline Age & & & $P=.04$ & & \\
\hline Age $\leq 65$ & 208 & $12(5.8 \%)$ & & & \\
\hline Age $>65$ & 164 & $20(12.2 \%)$ & & & \\
\hline Coronary artery disease & & & $P=.17$ & & \\
\hline No & 294 & $22(7.5 \%)$ & & & \\
\hline Yes & 78 & $10(12.8 \%)$ & & & \\
\hline Cause & & & $P=.01$ & & \\
\hline Atherosclerosis & 62 & $10(16.1 \%)$ & & 4.0 & $P=.003$ \\
\hline Dissection & 81 & $10(12.3 \%)$ & & 2.6 & $P=.048$ \\
\hline Others & 229 & $12(5.2 \%)$ & & & \\
\hline Diabetes & & & $P=.02$ & 5.1 & $P=.005$ \\
\hline No & 353 & $27(7.6 \%)$ & & & \\
\hline Yes & 19 & $5(26.3 \%)$ & & & \\
\hline CABG & & & $P=.17$ & & \\
\hline No & 293 & $22(7.5 \%)$ & & & \\
\hline Yes & 79 & $10(12.7 \%)$ & & & \\
\hline $\begin{array}{l}\text { Mitral valve replacement or other } \\
\text { concomitant procedures }\end{array}$ & & & $P=.17$ & & \\
\hline No & 355 & $29(8.2 \%)$ & & & \\
\hline Yes & 17 & $3(17.7 \%)$ & & & \\
\hline TCPT & & & $P=.03$ & & \\
\hline$\leq 20$ & 132 & $9(6.8 \%)$ & & & \\
\hline $20-40$ & 214 & $16(7.5 \%)$ & & & \\
\hline$>40$ & 26 & $7(26.9 \%)$ & & & \\
\hline
\end{tabular}

Factors that did not reach a $P$ value less than 0.2 in the univariate analyses: gender, reoperation, history of smoking, hypertension, neurologic history. Adverse outcome is defined as death or permanent stroke. For abbreviations see Table 1.

$\mathbf{P}_{\text {proximal aorta }}=\{1+\exp [3.06-1.62$ (diabetes)

$$
-1.37 \text { (atherosclerosis) }-0.91 \text { (dissection) }]\}^{-1}
$$

$\mathbf{P}_{\text {aortic arch }}=\{1+\exp [4.93-1.55$ (female)

$$
-1.87(\mathrm{CAD})-1.38(\text { diabetes })-0.024(\mathrm{TCPT})]\}^{-1}
$$

Different possible combinations of risk factors for elective proximal aortic surgery are shown in Table 5, with the probability for AO and the confidence intervals. A similar guide for estimating the risk of AO after aortic arch surgery in the presence of the most important independent variables is shown in Table 6.

\section{Discussion}

The results of surgery for aneurysms of the proximal thoracic aorta and aortic arch have generally improved in recent years. Most overall analyses result in the not surprising conclusion that emergency surgery is an overwhelming risk factor for death and other serious sequelae. Because most patients faced with an emergency operation because of rupture or dissection of the ascending aorta or arch will inevitably die without surgery, a careful weighing of other factors involved in the surgical risk is rarely possible for patients or physicians faced with this acute predicament. To make better-informed individualized decisions regarding the appropriateness of surgery in non-emergency situations, however, when rational scrutiny of different alternatives is still possible, examination of the factors that have an impact on AO exclusively in patients undergoing elective surgery seems appropriate. This is the rationale for the current study.

In studies looking at all aneurysm patients, including those who underwent emergency procedures, the extent of the operation clearly plays a major role in determining outcome. This may reflect an adverse impact of suboptimal cerebral protection during an extensive repair. Prolonged HCA time has been implicated as an important risk factor for AO (stroke and death ${ }^{6}$ ) and temporary neurologic dysfunction after surgery. ${ }^{7}$ For this reason, techniques have been evolving to keep the HCA time as short as possible. ${ }^{8}$ Some surgeons have relied increasingly on RCP, although its benefit is at best controversial. ${ }^{3,9,10}$ Others prefer selective $\mathrm{ACP}^{3,11-13}$ and use special cannulation techniques, ${ }^{14,15}$ especially when approaching the aortic arch. To compare operations using different cerebral protection techniques, we defined the term TCPT to include the time needed to accomplish the technical maneuvers requiring interruption of normal antegrade cardiopulmonary bypass. TCPT 


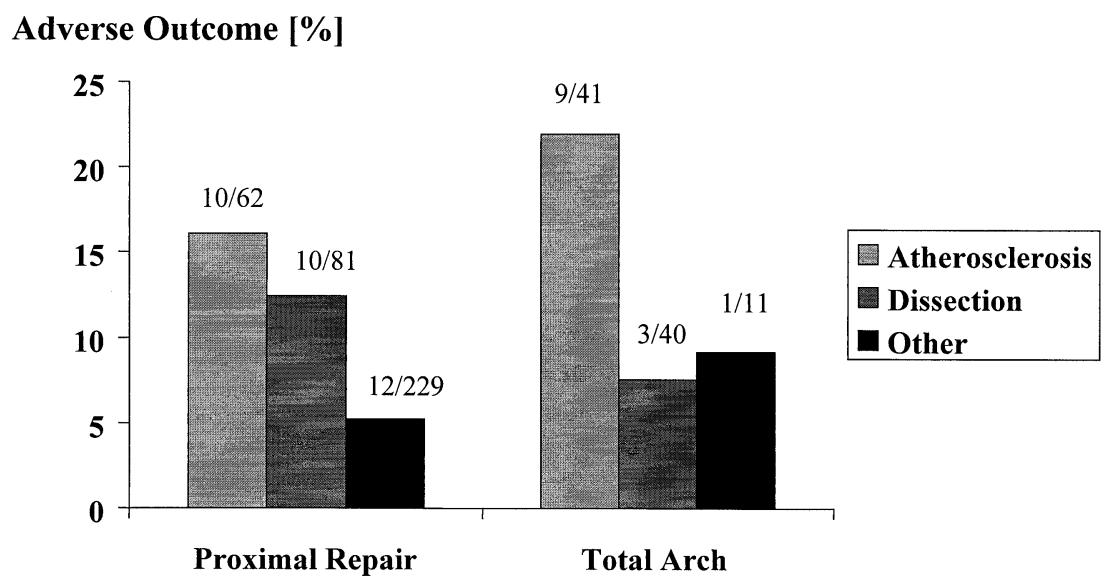

Figure 1. Impact of cause of aneurysm on adverse outcome (AO) (permanent stroke or hospital death) after elective surgery on the proximal ascending aorta or the aortic arch. Multivariate analysis revealed that atherosclerosis was a significant independent risk factor for $\mathrm{AO}$ after both operations, but that dissection was only a significant independent predictor of $\mathrm{AO}$ for proximal aortic surgery. The ratio of patients with $\mathrm{AO}$ to the number of patients undergoing operation is indicated for each category.

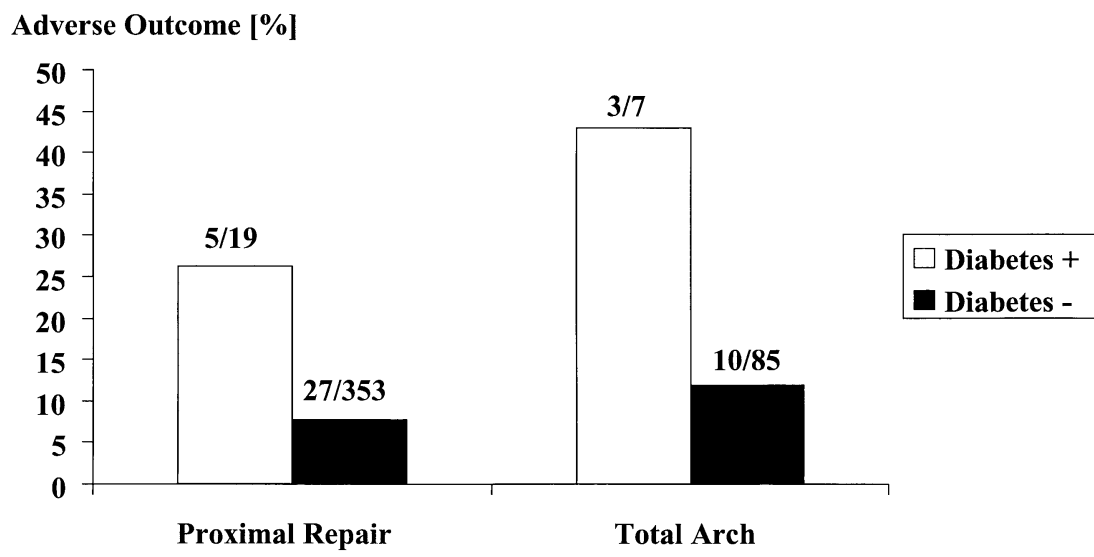

Figure 2. Impact of presence of diabetes on AO (permanent stroke or hospital death) after elective surgery on the proximal ascending aorta or the aortic arch. Multivariate analysis revealed that diabetes was a significant independent risk factor for $A O$ after proximal aortic surgery and was of marginal significance $(P=.13)$ as a predictor of $\mathrm{AO}$ for aortic arch surgery, partly because of the small numbers of patients involved. The ratio of patients with $A O$ to the number of patients undergoing operation is indicated for each category.

emerged as a strong risk factor for both stroke ${ }^{2}$ and temporary neurologic dysfunction ${ }^{16}$ in a large cohort including both elective and emergency operations.

We decided to perform 2 separate analyses to determine the independent risk factors for $\mathrm{AO}$ after elective operations for the group of patients who underwent elective surgery of the proximal thoracic aorta and for the group of patients who underwent more extensive aortic arch operations. From these analyses, we derived 2 equations in which the presence of each preoperative risk factor is registered by entering 1 into the formula on the basis of the patient's history.
Use of the equation for proximal aortic surgery is quite straightforward, relying entirely on patient-related factors. Use of the aortic arch equation requires estimation of the TCPT, which can quite easily be performed by an experienced surgeon. The contribution of TCPT to the equation is probably 2-fold: It reflects not only the extent of the operation but also the impact of the cerebral protection technique on outcome.

In both separate univariate analyses of patients undergoing elective aortic surgery, advanced age emerged as a risk factor for $\mathrm{AO}$, which is consistent with our own previous 
TABLE 4. Preoperative and intraoperative factors for adverse outcome in the univariate $(P<.2)$ and multivariate analysis of 92 patients who underwent elective aortic arch repair

\begin{tabular}{|c|c|c|c|c|c|}
\hline Preoperative factors & (n) & $\begin{array}{l}\text { Idverse outcome } \\
\text { number (\%) }\end{array}$ & Univariate & Odds ratio & Multivariate \\
\hline Gender & & & $P=.07$ & 4.7 & $P=.05$ \\
\hline Female & 35 & $8(22.9 \%)$ & & & \\
\hline Male & 57 & $5(8.8 \%)$ & & & \\
\hline Age & & & $P=.035$ & & \\
\hline Age $\leq 65$ & 40 & $2(5.0 \%)$ & & & \\
\hline Age $>65$ & 52 & $11(21.2 \%)$ & & & \\
\hline Coronary artery disease & & & $P=.02$ & 6.5 & $P=.02$ \\
\hline No & 74 & $7(9.5 \%)$ & & & \\
\hline Yes & 18 & $6(33.3 \%)$ & & & \\
\hline Reoperation & & & $P=.17$ & & \\
\hline No & 68 & $12(17.7 \%)$ & & & \\
\hline Yes & 24 & $1(4.2 \%)$ & & & \\
\hline Cause & & & $P=.07$ & & \\
\hline Atherosclerosis & 41 & $9(22.0 \%)$ & & & \\
\hline Dissection & 40 & $3(7.5 \%)$ & & & \\
\hline Others & 11 & $1(9.1 \%)$ & & & \\
\hline Diabetes & & & $P=.06$ & 4.0 & $P=.13$ \\
\hline No & 85 & $10(11.8 \%)$ & & & \\
\hline Yes & 7 & $3(42.9 \%)$ & & & \\
\hline TCPT & & & $P=.03$ & $1.02 / \mathrm{min}$ & $P=.03$ \\
\hline $\begin{array}{l}\leq 40 \\
40-80\end{array}$ & $\begin{array}{l}19 \\
58\end{array}$ & $1(5.3 \%)$ & & & \\
\hline $\begin{array}{l}40-80 \\
>80\end{array}$ & $\begin{array}{l}58 \\
15\end{array}$ & $\begin{array}{l}7(12.1 \%) \\
5(33.3 \%)\end{array}$ & & & \\
\hline
\end{tabular}

Factors that did not reach a $P$ value less than .2 in the univariate analyses: history of smoking, hypertension, neurologic history, additional coronary artery bypass grafting, and any other concomitant procedure. Adverse outcome is defined as death or permanent stroke.

TABLE 5. Predicted risk of adverse outcome after elective proximal aorta replacement, depending on the presence of significant independent risk factors: cause and diabetes

\begin{tabular}{lcc}
\hline & Diabetes & No diabetes \\
\hline Atherosclerosis & $48 \%(20,77)$ & $16 \%(9,27)$ \\
Dissection & $37 \%(15,65)$ & $10 \%(5,19)$ \\
Other cause & $19 \%(7,42)$ & $4 \%(2,8)$
\end{tabular}

Numbers in parenthesis represent $95 \%$ confidence limits. Adverse outcome is defined as death or permanent stroke.

findings ${ }^{2,7,16}$ and the findings of others. ${ }^{6}$ Advanced age is frequently associated with a higher amount of comorbidity, including chronic obstructive pulmonary disease, compensated kidney failure, and other serious diseases. Nevertheless, it should be noted that elective aortic surgery through a median sternotomy can be performed with an acceptable risk even in octogenarians, although the enhanced vulnerability of the brain in elderly patients is reflected by a high rate of temporary neurologic dysfunction and a high mortality after stroke. ${ }^{17}$ In the present study, although age was a significant risk factor in both univariate analyses, it did not emerge as significant from the multivariate studies. In this cohort, the effect of age was preempted by using atherosclerotic origin of the aneurysm as a risk factor or the presence of CAD. Specific information about the incidence of chronic obstructive pulmonary disease, which is also frequently present in patients with advanced age, was not available, especially among those undergoing operations during the earlier years of the study. This was unfortunate, because Okita and coworkers ${ }^{18}$ showed that chronic obstructive pulmonary disease is an independent risk factor for $\mathrm{AO}$ in patients undergoing aortic arch surgery using HCA.

We were somewhat surprised to find such a strong impact of diabetes on $\mathrm{AO}$, because we did not find diabetes to be a predictor for stroke, AO, or temporary neurologic dysfunction in any of our previous studies. Borger and coworkers $^{19}$ and Corbineau and associates ${ }^{20}$ showed that diabetes has an influence on outcome after extracorporeal circulation and coronary artery bypass surgery. We speculate that diabetes may have its impact as the result of macrovascular and microvascular changes: It is known that atherosclerosis is the leading cause of death in diabetic patients, probably as the result of stroke and myocardial infarction. ${ }^{21}$ Our rationale for keeping diabetes in the equation, although it did not reach statistical significance $(P=$ .13) in the multivariate regression model for aortic arch surgery, is based on the high AO among the very few patients with diabetes in this group (43\%) (Figure 2). Given the finding that diabetes was a strong predictor of $\mathrm{AO}$ among patients with elective proximal repair (26\% AO), we 
TABLE 6. Predicted risk of adverse outcome after elective aortic arch replacement, depending on estimated TCPT and presence or absence of other significant risk factors

\begin{tabular}{|c|c|c|c|c|c|}
\hline \multirow[b]{2}{*}{ No CAD } & \multirow[b]{2}{*}{ TCPT (min) } & \multicolumn{2}{|c|}{ Female } & \multicolumn{2}{|c|}{ Male } \\
\hline & & Diabetes & No diabetes & Diabetes & No diabetes \\
\hline & 20 & $18 \%(3,61)$ & $5 \%(1,20)$ & $4 \%(0.5,31)$ & $1 \%(0.2,7)$ \\
\hline & 40 & $26 \%(5,68)$ & $8 \%(3,23)$ & $7 \%(0.9,38)$ & $2 \%(0.3,8)$ \\
\hline & 60 & $36 \%(9,77)$ & $12 \%(5,28)$ & $11 \%(1,49)$ & $3 \%(0.7,12)$ \\
\hline & 80 & $47 \%(14,84)$ & $19 \%(8,38)$ & $16 \%(2,62)$ & $5 \%(1,17)$ \\
\hline \multirow[t]{5}{*}{ CAD } & TCPT (min) & Diabetes & No diabetes & Diabetes & No diabetes \\
\hline & 20 & $59 \%(12,93)$ & $26 \%(0.4,73)$ & $23 \%(40,71)$ & $7 \%(1,30)$ \\
\hline & 40 & $70 \%(21,95)$ & $36 \%(9,78)$ & $33 \%(6,78)$ & $11 \%(3,35)$ \\
\hline & 60 & $79 \%(32,97)$ & $48 \%(15,83)$ & $44 \%(11,84)$ & $16 \%(5,43)$ \\
\hline & 80 & $86 \%(42,98)$ & $60 \%(23,88)$ & $56 \%(16,89)$ & $24 \%(8,54)$ \\
\hline
\end{tabular}

Numbers in parentheses are $95 \%$ confidence limits. Adverse outcome is defined as death or permanent stroke. CAD, Coronary artery disease.

believed that to disregard diabetes in the aortic arch risk stratification would be misleading.

In the current study, atherosclerosis was associated with an $\mathrm{AO}$ of $16 \%$ for elective proximal aortic repair and $22 \%$ for elective total arch replacement. In patients with CAD who underwent total arch replacement, the outcome was especially dismal. The negative impact of an atherosclerotic aorta on outcome after cardiac surgery is well known. ${ }^{22}$ Davila-Roman and coworkers ${ }^{23}$ found that atherosclerosis of the ascending aorta was an independent predictor of long-term neurologic sequelae and mortality in 1957 consecutive patients aged more than 50 years at the time of cardiac surgery. The current study provides additional evidence that an atherosclerotic ascending aorta, in addition to being worrisome as a direct cause of cerebral atheroembolism, may be a marker of generalized atherosclerosis, and therefore predicts increased postoperative morbidity and mortality.

The fact that dissection poses an increased risk of AO of elective surgery in the proximal arch was somewhat unexpected and is probably attributable to a combination of factors. Often, there is considerable thrombus in chronic dissections, predisposing the patient to embolization. A significant proportion of the chronic dissections in this series were reoperations, in which there was a potential of dislodging neointimal material if cannulation was performed through a previous graft. The data also reveal that operations for dissection required longer intervals of HCA than other proximal aorta replacements. We speculate that this may be the result of the time required to remove thrombus from the origins of the cerebral vessels and to explore each vessel to be sure that the graft would perfuse the true lumen unobstructed. The abandonment of femoral and even of central cannulation in favor of an approach through the axillary artery should reduce the future risk of embolic events. Improvements in cerebral protection, including use of selective cerebral perfusion rather than pro- longed HCA, should enable more extensive resections in chronic dissections to be performed safely. In this regard, it is of interest that chronic dissection was not a risk factor for AO among patients with complete arch replacements.

Another interesting observation to emerge from this study is that women with a combination of diabetes and $\mathrm{CAD}$ are at an especially high risk for $\mathrm{AO}$ after aortic arch surgery, even when the TCPT does not exceed 40 minutes. For a man with the same risk factors, an aortic arch operation can be performed with one third the risk (Table 6).

From a surgical point of view, it seems that the strategies for cerebral protection used for the short intervals required for surgery of the proximal aorta are usually effective. But the longer intervals that must be used in some proximal aorta operations and in many of those in the aortic arch still pose a problem and significantly contribute to $\mathrm{AO}$. It is also clear that several strategies should be implemented to minimize the incidence of embolic events, especially in very high-risk patients. To reduce the possibility of retrograde embolization from the femoral artery, the right or left axillary artery (both usually free of atheroma) can be cannulated for cardiopulmonary bypass. Manipulation, crossclamping, and insertion of cannulas into potentially diseased vessels should be avoided. Use of separate grafts anastomosed to individual cerebral vessels cranial to their origin from the aortic arch, in an area more likely to be free of atherosclerosis, may further reduce the rates of cerebral embolization during aortic arch surgery in high-risk patients.

\section{Conclusion}

Although emergency surgery has an overwhelming negative impact on mortality and morbidity after operations on the ascending aorta and aortic arch, other serious risk factors can be identified that may influence patients and physicians making decisions about elective surgery. Independent risk factors contributing significantly to $\mathrm{AO}$ in patients undergoing elective surgery include the presence of diabetes and 
atherosclerosis. For surgery of the proximal aorta, the presence of dissection is the only other additional independent risk factor. For arch surgery, the presence of CAD, female sex, and estimated TCPT are additional factors that contribute independently to AO. For each type of operation, these factors can be combined in equations that will result in an individualized estimate of risk of elective surgery involving either replacement of the proximal ascending aorta or more extensive aortic arch repair. Improvements in surgical technique may reduce the future impact of some of these risk factors on the outcome of elective surgery, and further scrutiny of surgical results will likely result in refinements of these formulations to improve their predictive value and validate their accuracy. Nevertheless, even given their limitations, equations such as these should allow more informed decisions regarding aneurysm surgery, including the consideration of conservative approaches for some especially high-risk patients.

\section{References}

1. Coady MA, Rizzo JA, Hammond GL, et al. What is the appropriate size criterion for resection of thoracic aortic aneurysms? J Thorac Cardiovasc Surg. 1997;113:476-91.

2. Hagl C, Ergin MA, Galla JD, et al. Neurologic outcome after ascending aorta-aortic arch operations: effect of brain protection technique in high-risk patients. J Thorac Cardiovasc Surg. 2001;121:1107-21.

3. Griepp RB, Ergin MA, McCullough JN, et al. Use of hypothermic circulatory arrest for cerebral protection during aortic surgery. J Card Surg. 1997;12:312-21.

4. McCullough JN, Zhang N, Reich DL, et al. Cerebral metabolic suppression during hypothermic circulatory arrest in humans. Ann Thorac Surg. 1999;67:1895-1921.

5. Ehrlich MP, Hagl C, McCullough JN, et al. Retrograde cerebral perfusion provides negligible flow through brain capillaries in the pig. J Thorac Cardiovasc Surg. 2001;122:331-8.

6. Svensson LG, Crawford ES, Hess KR, et al. Deep hypothermia with circulatory arrest: determinants of stroke and early mortality in 656 patients. J Thorac Cardiovasc Surg. 1993;106:19-31.

7. Ergin MA, Uysal S, Reich DL, et al. Temporary neurological dysfunction after deep hypothermic circulatory arrest: a clinical marker of long-term functional deficit. Ann Thorac Surg. 1999;67:1887-94.

8. Griepp RB. Cerebral protection during aortic arch surgery. J Thorac Cardiovasc Surg. 2001;121:425-7.
9. Bavaria JE, Woo YJ, Hall RA, et al. Retrograde cerebral and distal aortic perfusion during ascending and thoracoabdominal aortic operations. Ann Thorac Surg. 1995;60:345-53.

10. Coselli JS. Retrograde cerebral perfusion in surgery for aortic arch aneurysms. In: Ennker J, Coselli JS, Hetzer R, editors. Cerebral protection in cerebrovascular and aortic surgery. Darmstadt, Germany: Steinkopf Verlag; 1997. pp 239-49.

11. Bachet J, Guilmet D, Goudot B, et al. Antegrade cerebral perfusion with cold blood: a 13-year experience. Ann Thorac Surg. 1999;67: 1874-94.

12. Kazui T, Washiyama N, Muhammad BA, et al. Improved results of atherosclerotic arch aneurysm operations with a refined technique. J Thorac Cardiovasc Surg. 2001;121:491-9.

13. Dossche KM, Schepens MAAM, Moshuis WJ, et al. Antegrade selective cerebral perfusion in operations on the proximal thoracic aorta. Ann Thorac Surg. 1999;67:1904-10.

14. Katoh T, Gohra H, Hamano K, et al. Right axillary cannulation in the left thoracotomy for thoracic aortic aneurysm. Ann Thorac Surg. 2000;70:311-3.

15. Baribeau YR, Westbrook BM, Charlesworth DC. Axillary cannulation: first choice for extra-aortic cannulation and brain protection. J Thorac Cardiovasc Surg. 1999;118:1153-4.

16. Ehrlich MP, Ergin MA, McCullough JN, et al. Predictors of adverse outcome and transient neurological dysfunction after ascending aorta/ hemiarch replacement. Ann Thorac Surg. 2000;69:1755-63.

17. Hagl C, Galla JD, Spielvogel D, et al. Is aortic surgery using hypothermic circulatory arrest in octogenarians justifiable? Eur J Cardiothorac Surg. 2001;19:417-23.

18. Okita Y, Takamoto S, Ando M, et al. Mortality and cerebral outcome in patients who underwent aortic arch operations using deep hypothermic circulatory arrest with retrograde cerebral perfusion: no relation of early death, stroke, and delirium to the duration of circulatory arrest. J Thorac Cardiovasc Surg. 1998;115:129-38.

19. Borger MA, Ivanov J, Weisel RD, et al. Stroke during coronary bypass surgery: principal role of cerebral macroemboli. Eur J Cardiothorac Surg. 2001;19:627-32.

20. Corbineau H, Lebreton H, Langanay T, et al. Prospective evaluation of coronary arteries: influence on operative risk in coronary artery surgery. Eur J Cardiothorac Surg. 1999;16:429-34.

21. Burchfiel CM, Reed DM, Marcus EB, et al. Association of diabetes mellitus with coronary atherosclerosis and myocardial lesions. An autopsy study from the Honolulu Heart Program. Am J Epidemiol. 1993;137:1328-40.

22. Vaage J, Jensen U, Ericsson A. Neurologic injury in cardiac surgery: aortic atherosclerosis emerges as the single most important risk factor. Scand Cardiovasc J. 2000;34:550-7.

23. Davila-Roman VG, Murphy SF, Nickerson NJ, et al. Atherosclerosis of the ascending aorta is an independent predictor of long-term neurologic events and mortality. J Am Coll Cardiol. 1999;33:1308-16. 